J. Lake Sci.(湖泊科学), 2020, 32(4): 952-963

DOI 10. 18307/2020. 0405

(c) 2020 by Journal of Lake Sciences

\title{
雄安新区一白洋淀冰封期水体污染特征及水质评价”
}

\author{
孙悦, 李再兴, 张艺再, 周石䂞坏, 战 江, 王函, 尹 璐, 郭朋朋 \\ (河北科技大学环境科学与工程学院, 河北省污染防治生物技术实验室, 石家庄 050018)
}

\begin{abstract}
摘 要: 为明确白洋淀冬季冰封期水污染特征, 于 2019 年 1 月对白洋淀原始区、旅游区、生活区、养殖区和人淀区 5 个特 征区域 25 个代表性采样点进行水样采集,选取温度、溶解氧 $(\mathrm{DO}) 、$ 、氨氮 $\left(\mathrm{NH}_{3}-\mathrm{N}\right) 、$ 、亚硝态氮 $\left(\mathrm{NO}_{2}^{-}-\mathrm{N}\right)$ 、硝态氮 $\left(\mathrm{NO}_{3}^{-}-\mathrm{N}\right)$ 、 总氮 $(\mathrm{TN})$ 、总磷 $(\mathrm{TP})$ 、高锰酸盐指数作为评价因子, 采用单因子评价法、综合污染指数 $(K)$ 法和主成分分析法对水质进 行综合评价. 结果表明: 白洋淀冰封期不同功能区水体温差波动较小, DO 浓度变化幅度大, TN 和 TP 浓度较高. 单因子评 价表明, $\mathrm{TN}$ 参与评价时, 25 个采样点中, III类水体占 $28 \%$, 其余为 $\mathrm{IV}$ 类、 $\mathrm{V}$ 类和劣 $\mathrm{V}$ 类; $\mathrm{TP}$ 参与评价时, III类水体占 $16 \%$, 其余为 $\mathrm{I}$ 类、 $\mathrm{V}$ 类和劣 $\mathrm{V}$ 类, 综合看, 白洋淀水质整体状况较差; 综合污染指数法表明,生活区水质最好, 人淀区河流水质 最差, 其中白沟引河、府河和瀑河 3 条人淀口河流水质状况最差, 为重度污染, 主要污染物为 TN、TP; 主成分分析法表明, 人淀区的 6 条河流彼此间偏差较大,所受污染的影响因子存在较大差异,与主成分 1 和主成分 2 高度相关的理化指标是 TN 、TP. 通过 3 种评价方法定性定量的有机结合, 得出白洋淀冬季冰封期水质限制因子为 TN、TP 且该时期水体污染较严 重, 冰封期作为湖泊水体的重要时期, 探明污染源并治理可显著改善湖泊水质, 不仅为白洋淀水体治理提供最佳时机, 也 为治理和修复淀区水体污染提供指导意义.
\end{abstract}

关键词: 白洋淀;冰封期;水污染特征;单因子评价法;综合污染指数 $(K)$ 法; 主成分分析法

\section{Water pollution characteristics and water quality evaluation during the freezing period in Lake Baiyangdian of Xiong'an New Area*}

SUN Yue, LI Zaixing, ZHANG Yiran, ZHOU Shilei ${ }^{* *}$, ZHAN Jiang, WANG Han, YIN Lu \& GUO Pengpeng (Pollution Prevention Biotechnology Laboratory of Hebei Province, School of Environmental Science and Enginnering, Hebei University of Science and Technology, Shijiazhuang 050018, P.R.China)

Abstract: Twenty-five water sampling sites in Lake Baiyangdian were selected to investigate the characteristics of water quality in January 2019, including primitive area, tourist rea, living area, aquaculture area and enter area. Temperature, dissolved oxygen (DO), ammonia nitrogen $\left(\mathrm{NH}_{3}-\mathrm{N}\right)$, nitrous oxide nitrogen $\left(\mathrm{NO}_{2}^{-}-\mathrm{N}\right)$, nitrate nitrogen $\left(\mathrm{NO}_{3}^{-}-\mathrm{N}\right)$, total nitrogen $(\mathrm{TN})$, total phosphorus (TP), permanganate index were used as factors to evaluate water quality based on the single factor evaluation method, comprehensive pollution index $(K)$ method and principal component analysis method, respectively. The results indicated that temperature of the lake had a minor fluctuation, the DO exhibited a huge variation, TN and TP presented high concentrations during the freezing period in Lake Baiyangdian. The single factor evaluation showed that when TN was used for evaluation, Class III water bodies accounted for $28 \%$, and the rest were Class IV, Class V and lower V among the 25 sampling points. When TP was used, Class III water bodies accounted for 16\%, and the rest were IV, Class V and lower V. Overall, the quality of Lake Baiyangdian water was relatively poor. The comprehensive pollution index method showed that water quality in the living area was better, while the enter area was worse. The water quality of Baigou River, Fuhe River and Puhe River were the worst among all sampling sites, which belonged to heavy pollution rivers involved to TN and TP. The principal component analysis indicated that the six rivers of the sedimentation area had large deviations in water quality and pollution influencing factors. TN and TP were highly correlated with PCA1 and PCA2 in the physical and chemical indicators. Overall, the evaluation combined qualitative and quantitative methods

* 2019-06-24 收稿; 2019-11-27 收修改稿.

国家自然科学基金项目 (51909056)、河北省研究生创新项目 (CXZZSS2019080, CXZZSS2018084) 和河北科技大学 引进人才科研启动基金项目 (1181278) 联合资助.

** 通信作者;E-mail:ZSLZhouShilei@ 126.com. 
showed that the TN and TP were the main limiting factor in freezing period of Lake Baiyangdian. From all the results, the freezing period is important for lake water bodies, probing the source of pollution and controlling it can significantly improve the water quality of the lake. The series of researches not only offers the best opportunity for the treatment of water, but also provides guidance for the treatment and restoration of water pollution in Lake Baiyangdian.

Keywords: Lake Baiyangdian; freezing period; pollution characteristics; single factor evaluation method; comprehensive pollution index $(K)$ method; principal component analysis method

白洋淀位于雄安新区的核心位置, 在拦蓄洪水、航运渔业和调节气候等方面意义重大,为雄安新区的建 设提供了重要的生态保障. 目前, 针对白洋淀的研究主要集中在淀区生态系统健康评价、动植物群落与水体 富营养化关系调查及沉积物氮素分布与释放通量研究等方面, 例如 $\mathrm{Xu}$ 等 ${ }^{[1]}$ 根据白洋淀水域生态健康状况 的典型特征, 应用热力学指标体系的生态系统健康评价方法对白洋淀生态系统健康状况进行评价, 确定了 研究水域的健康状况, 针对人类干扰较多的水域提出了相应的措施; 李华等 ${ }^{[2]}$ 构建了白洋淀底栖一浮游耦合 食物网的概念模型, 探究富营养化对底栖、浮游食物网的影响, 结果表明浮游植物与总氮 (TN) 浓度呈显著 的正相关关系, 而底栖藻类和大型沉水植物与 $\mathrm{TN}$ 、总磷 ( TP) 浓度呈显著负相关关系; Zhu 等 ${ }^{\left[{ }^{3}\right]}$ 采集了 34 个 沉积物样本, 应用一维孔隙水扩散模型计算氨氮释放通量, 结果表明氨氮在沉积物中释放的可能性较大, 对 于白洋淀底栖生物的影响比其他形式的氮更为显著.

为了更好地保护白洋淀水生态系统, 需要对白洋淀水体水质特征及污染状况进行全面系统的分析和评 价. 而现有研究针对白洋淀水质的研究和评价, 大多以单一或部分淀区为对象、评价方法单一且采样时间大 多集中在春、夏、秋季节. 例如,Zhao 等 ${ }^{[4]}$ 虽然研究了白洋淀 8 个采样点十年内水质变化, 但仅采用了综合污 染指数法对理化指标进行处理分析, 得出 TN、TP 是影响白洋淀富营养化的主要污染物; 王瑜等 ${ }^{[5]}$ 应用修正 的卡尔森营养指数和优势种评价法对苯林庄、端村春、夏季水质进行分析, 结果显示两个淀区的水体处于中 度富营养状态; $\mathrm{Qi}$ 等 ${ }^{[6]}$ 利用综合污染指数对府河水质进行评价, 结果显示府河内 TN、TP 综合污染指数较 高, 说明控制府河水质是缓解白洋淀富营养化程度的关键. 冰封期作为雄安新区一白洋淀水质变化的一个重 要时期,一方面冬季水草死亡腐烂释放 $\mathrm{N} 、 \mathrm{P}$ 等污染物且温度降低冰体中污染物向下覆水迁移, 导致区域水 体污染物浓度升高; 另一方面冰层通过隔绝大气与水面的氧传递, 导致水体溶解氧浓度下降, 沉积物在厌氧 条件下释放大量内源污染物, 导致水质污染严重. 然而, 目前关于白洋淀冰封期水体水质特征及污染状况的 研究却鲜有报道. 因此, 全面分析白洋淀冰封期水体水质, 并应用科学的评价方法明确水体水质状况变得十 分必要, 不仅可以填补冬季冰封期水体水质数据、健全白洋淀水质基础数据库; 而且还为分析该时期水质演 变的微生物作用机制以及定向精准治理白洋淀奠定坚实的基础.

目前, 常用的水质评价方法主要有单因子评价法 ${ }^{[7-9]}$ 、综合污染指数法 ${ }^{[7,10]}$ 、主成分分析法 ${ }^{[11-12]}$ 、模糊综 合评价法 ${ }^{[13]}$ 、水质指数法 ${ }^{[14]}$ 等, 这些评价方法各有优缺点, 侧重点也不同. 为明确各淀区冰封期水质特征, 根据白洋淀整体淀区的承载功能, 将整个淀区分为五大功能区即原始区、旅游区、生活区、养殖区和人淀区, 并在 5 个特征区域内设置 25 个代表性采样点, 研究各个淀区的水体水质特征; 并综合单因子评价法、综合污 染指数法以及主成分分析法对该时期水体进行分析,旨在明确冰封期淀区水污染状况.

\section{1 材料与方法}

\section{1 研究区概况}

白洋淀位于河北省中部, 总面积达 $366 \mathrm{~km}^{2}$, 流域面积为 $31200 \mathrm{~km}^{2}$, 作为华北平原最大的淡水湖泊, 对 维护华北地区生态系统平衡、调节华北平原乃至京津地区气候、补充地下水源、调蓄洪水以及保护生物物种 多样性等方面发挥重要作用 ${ }^{[4,15]}$. 淀内主要由大小不等的 143 个淀泊和 3700 多条沟壕组成, 形成了“淀中有 村, 村中有淀” 的独特景象 ${ }^{[16]}$, 随着雄安新区的设立, 白洋淀作为新区最重要的水域之一, 其内部规划和水 环境状况更是受到各界的关注.

\section{2 研究区划分及采样点设置}

通过现场调查及前人研究 ${ }^{[17-20]}$, 根据各淀区的承载功能将白洋淀分为原始区、旅游区、生活区、养殖区、 
人淀区 5 个特征区域, 每个功能区均有其各自的特征 (表 1 ), 原始区包括藻苲淀 $1^{\#}(\mathrm{~S} 1)$ )、藻苲淀 $2^{\#}(\mathrm{~S} 2)$ 、藻 苲淀 $3^{\#}(\mathrm{~S} 3) 3$ 个采样点; 旅游区包括烧车淀 (S4)、鹗䒧岛一旅游区 (S5)、文化苑西门 (S6) 3 个采样点; 生活 区包括束林庄 $(\mathrm{S} 7)$ 、平阳淀 $(\mathrm{S} 8)$ 、小麦淀 $(\mathrm{S} 9)$ 、北田庄西淀 $(\mathrm{S} 10)$ 、涝王淀 $(\mathrm{S} 11)$ 、采蒲台 $(\mathrm{S} 12)$ 、范峪淀 (S13) 7 个采样点; 养殖区包括前塘 (S14)、后塘 (S15)、端村 $1^{\#}(\mathrm{~S} 16) 、$ 端村 $2^{\#}(\mathrm{~S} 17)$ 、泛鱼淀 (S18)、鲥穌淀 (S19) 5 个采样点; 人淀区包括白沟引河 (S20)、瀑河藻荐淀人淀口 (S21)、萍河藻荐淀人淀口 (S22)、唐河端 村人淀口 (S23)、南刘庄府河人淀口 (S24)、潴笼河人淀口 (S25) 6 个采样点. 每个区域的采样点位置见图 1, 于 2019 年 1 月对 25 个采样点的表层水样进行采集, 由于北方冬季气温较低, 河水冻结, 现场丵冰利用采水 器进行各采样点表层水样的采集,利用 DS5 水质分析仪现场测定温度、电导率等基本指标.

表 1 白洋淀冰封期 5 大功能区特征

Tab. 1 Characteristics of five functional zones in Lake Baiyangdian during freezing period

\begin{tabular}{ccc}
\hline 功能区 & 采样点 & 功能区特征 \\
\hline 原始区 & $\mathrm{S} 1 \sim \mathrm{S} 3$ & 人烟稀少, 人类干预较少 \\
旅游区 & $\mathrm{S} 4 \sim \mathrm{S} 6$ & 区内设旅游景点,接纳大批游客 \\
生活区 & $\mathrm{S} 7 \sim \mathrm{S} 13$ & 村庄依水而建, 区内生活大量居民 \\
养殖区 & $\mathrm{S} 14 \sim \mathrm{S} 19$ & 区内水产养殖业发达 \\
人淀区 & $\mathrm{S} 20 \sim \mathrm{S} 25$ & 6 条河流连接白洋淀与外界河流 \\
\hline
\end{tabular}

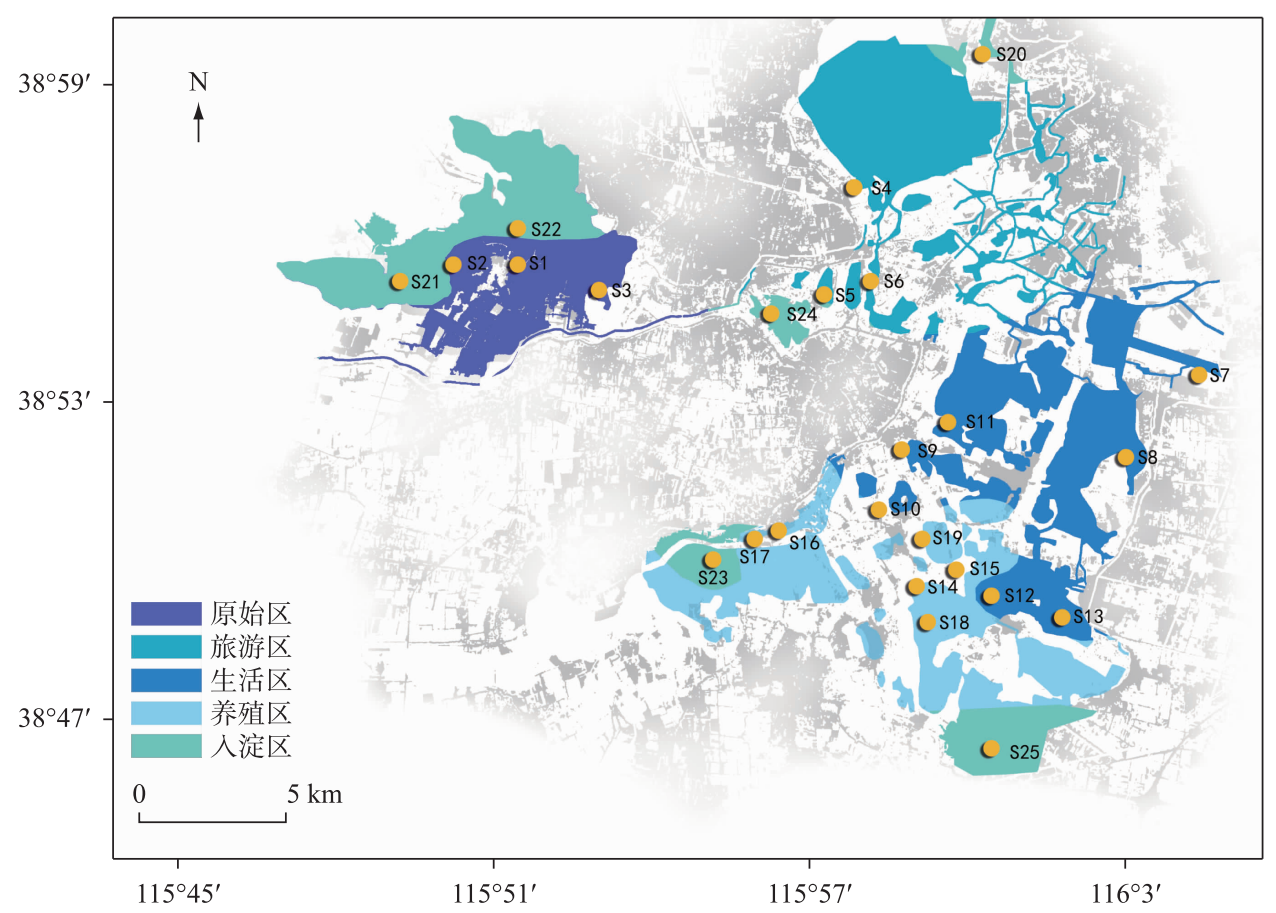

图 1 白洋淀采样点示意

Fig. 1 Distribution of sampling sites of Lake Baiyangdian

\section{3 测定方法}

本研究测定了白洋淀 5 个特征区域 25 个水样的 8 个水质指标, 其中温度、溶解氧 (DO) 浓度利用多参数 水质分析仪现场测定, 高锰酸盐指数采用酸性法测定, 氨氮 $\left(\mathrm{NH}_{3}-\mathrm{N}\right)$ 浓度采用纳氏试剂光度法测定, 亚硝态 氮 $\left(\mathrm{NO}_{2}^{-}-\mathrm{N}\right)$ 浓度采用 $\mathrm{N}-(1$ - 䒬基 $)$-乙二胺光度法, 硝态氮 $\left(\mathrm{NO}_{3}^{-}-\mathrm{N}\right)$ 浓度采用紫外分光光度法, 总氮 $(\mathrm{TN})$ 浓度 采用过硫酸钾氧化一紫外分光光度法测定, 总磷 (TP) 浓度采用钼锑抗分光光度计法测定 ${ }^{[21]}$. 


\section{4 数据处理与评价方法}

将所得实验数据利用 Excel 2016 进行处理, Origin 2018 软件进行图形的绘制与分析, SPASS 22.0 进行主 成分中成分得分系数矩阵的数值分析.

本文选用单因子评价法、综合污染指数 $(K)$ 法、主成分分析法进行水质评价, 单因子评价法是最基本的 水质评价方法, 通过将某一指标作为分析变量, 可以简单直观的对 25 个采样点的水质进行定量分析; 综合 污染指数 $(K)$ 法通过较简单的数值分析可以对比不同河段水体的水质污染程度; 主成分分析法较为复杂, 但 是能够对 5 个淀区的整体情况进行定性分析, 3 种评价方法相结合可以客观准确的对白洋淀冰封期水质进 行评价.

1.4.1 单因子评价法 单因子评价法采用一票否决原则, 将各评价指标的检测浓度与评价标准进行对比, 将 最差指标的水质类别作为评价结果进行后续分析. 在所有参评水质指标中, 如有一项指标超标, 则所属水域 不符合相应的水质标准 ${ }^{[22]}$.

1.4.2 综合污染指数法 综合污染指数 $(K)$ 法是我国第一个综合表示水质污染情况及综合评价水污染的方 法, 它用一种简单的, 可以进行统计的数值来评价水质污染情况. 在空间上可以对比不同河段水体的水质污 染程度,便于分级分类; 在时间上可以表示一个河段,一个地区水质污染的总的变化趋势, 其表达式是 ${ }^{[23]}$ :

$$
K=\sum C_{i} \cdot C_{k} / C_{\text {oi }}
$$

式中, $C_{i}$ 指各类污染物的实测浓度 $(\mathrm{mg} / \mathrm{L})$; $C_{o i}$ 指各类污染物评价标准值; $C_{k}$ 指地表水各类污染物的统一标 准值, 此值为 0.1 . 综合污染指数法评价分级标准包括 6 个标准: $K \leqslant 0.1$ 的水体属于一般或未受污染水体、 $0.1<K \leqslant 0.2$ 属于微度污染水体、 $0.2<K \leqslant 0.5$ 属于轻度污染水体、 $0.5<K \leqslant 1.0$ 属于中度污染水体、 $1.0<K \leqslant 5.0$ 属于重度污染水体、 $K>5.0$ 时属于严重污染水体.

1.4.3 主成分分析法 主成分分析法实际是利用降维的思想,通过全面分析各项指标所携带的信息,笁选出 比原始指标少,但能解释大部分资料的综合性指标 ${ }^{[11,24]}$.

\section{2 结果与讨论}

\section{1 水质因子特征}

2.1.1 理化和营养盐指标 图 2 显示了白洋淀冰封期各采样点的基本水质指标情况, 白洋淀冰封期各采样点 的水温在 $1.76 \sim 5.84^{\circ} \mathrm{C}$ 间, 各淀区水体间温差波动较小; 由图 $2 \mathrm{~b}$ 可知, $\mathrm{DO}$ 浓度在各个采样点之间相差较大, 其中原始区的 S2 采样点 DO 浓度为 $9.82 \mathrm{mg} / \mathrm{L}$, 高于地表水质量标准 I 类限值 $(7.5 \mathrm{mg} / \mathrm{L})$, 可能是原始区靠 近人淀区河流, 冬季人淀区河流流动频繁, 水体中 DO 浓度较多, 导致汇人 S2 中的 DO 浓度较高; 位于生活 区的 S8 采样点 DO 浓度最低, 为 $0.53 \mathrm{mg} / \mathrm{L}$, 可能是冰封期河流结冰, 一方面水体流动缓慢, 另一方面冰面阻 隔了大气与水体中氧的传质, 使得淀区中 DO 浓度降低. 氨氮浓度范围为 $0.09 \sim 0.74 \mathrm{mg} / \mathrm{L}$, 水中氨氮的来源 主要为生活污水中含氮有机物受微生物作用的分解产物, 其中 S 20 白沟引河采样点氨氮浓度最高, 为 0.74 $\mathrm{mg} / \mathrm{L}, \mathrm{S} 20$ 位于人淀区的位置,一方面杨静等 ${ }^{[25]}$ 通过对白洋淀流域养分流失研究发现随着白洋淀周边城市 化进程的加快, 会导致河流受到的污染更为严重, 白沟引河周边分布较多居民, 随着冰封期水面结冰, 水体 中汇人的生活垃圾等外源污染物扩散缓慢, 逐渐沉降至下覆水中, 造成所在区域水体中氨氮浓度较高; 其次 该采样点随着时间的积累沉积了大量水生植物的腐败物, 导致内源污染物大量释放; 再次是上游人淀区河 流的氨氮浓度较高, 虽已进人冰封期, 但该采样点仍与上游河流进行水质交流, 导致水质污染严重. 图 $2 \mathrm{~d}$ 显 示各功能区的 TN 浓度变化波动较大, 人淀区 6 个采样点的 TN 浓度均较高, $\mathrm{S} 24$ 的 TN 浓度高达 $8.13 \mathrm{mg} / \mathrm{L}$, 污染最为严重, S24 采样点作为承接保定市废水的河流, 水质呈现出中度富营养状态, 在不具备富营养化条 件的冰封期, TN 浓度依旧最高, 一方面是冰体中污染物逐渐向下覆水迁移, 另一方面可能是内源释放造成 水质污染严重, 这也将导致融冰期含氮污染物扩散加快, 水质富营养化更加严重.

根据现场调研可知虽已进人冰封期, 但 6 条人淀区河流仍与上游河流存在水质流动, 由于白洋淀地势 平缓, 冰封期水体流动更加缓慢, 因此外界河流汇人的污染物几乎汇聚在各人淀区河流, 从而导致冰封期的 6 条人淀区河流污染显著; TP 浓度变化范围在 $0.04 \sim 1.62 \mathrm{mg} / \mathrm{L}$ 之间, 与 $\mathrm{TN}$ 浓度呈现出的结果类似. 通过现 场调研及对冰封期各采样点理化和营养盐指标分析可知, 白洋淀地势平缓且冰封期各淀区水质流动缓慢, 
从而导致外源污染物几乎汇聚在各人淀区河流, 人淀区高浓度的氮、磷浓度在融冰期随着河水流动速度的 加快,可能导致白洋淀大面积水域受到污染,因此应加紧对人淀区河流的治理.

2.1.2 有机污染指标 高镇酸盐指数常被作为地表水体受有机污染物和还原性无机物质污染程度的综合指 标, 图 $2 \mathrm{f}$ 显示高镇酸盐指数的变化范围在 4.74 $8.76 \mathrm{mg} / \mathrm{L}$ 之间, $80 \%$ 的采样点高于 $6 \mathrm{mg} / \mathrm{L}$ ( III 类水质标准 限值), 位于养殖区的 S15 采样点高锰酸盐指数值最高, 为 $8.76 \mathrm{mg} / \mathrm{L}$, 可能是养殖区水域大面积发展鱼虾, 历史上剩余饵料堆积沉人底层 ${ }^{[4,26]}$, 随着冰封期的来临, 水体中 DO 浓度下降, 导致沉积物中的污染物质在 厌氧的条件下释放到上覆水中, 使得冰封期水体污染严重.
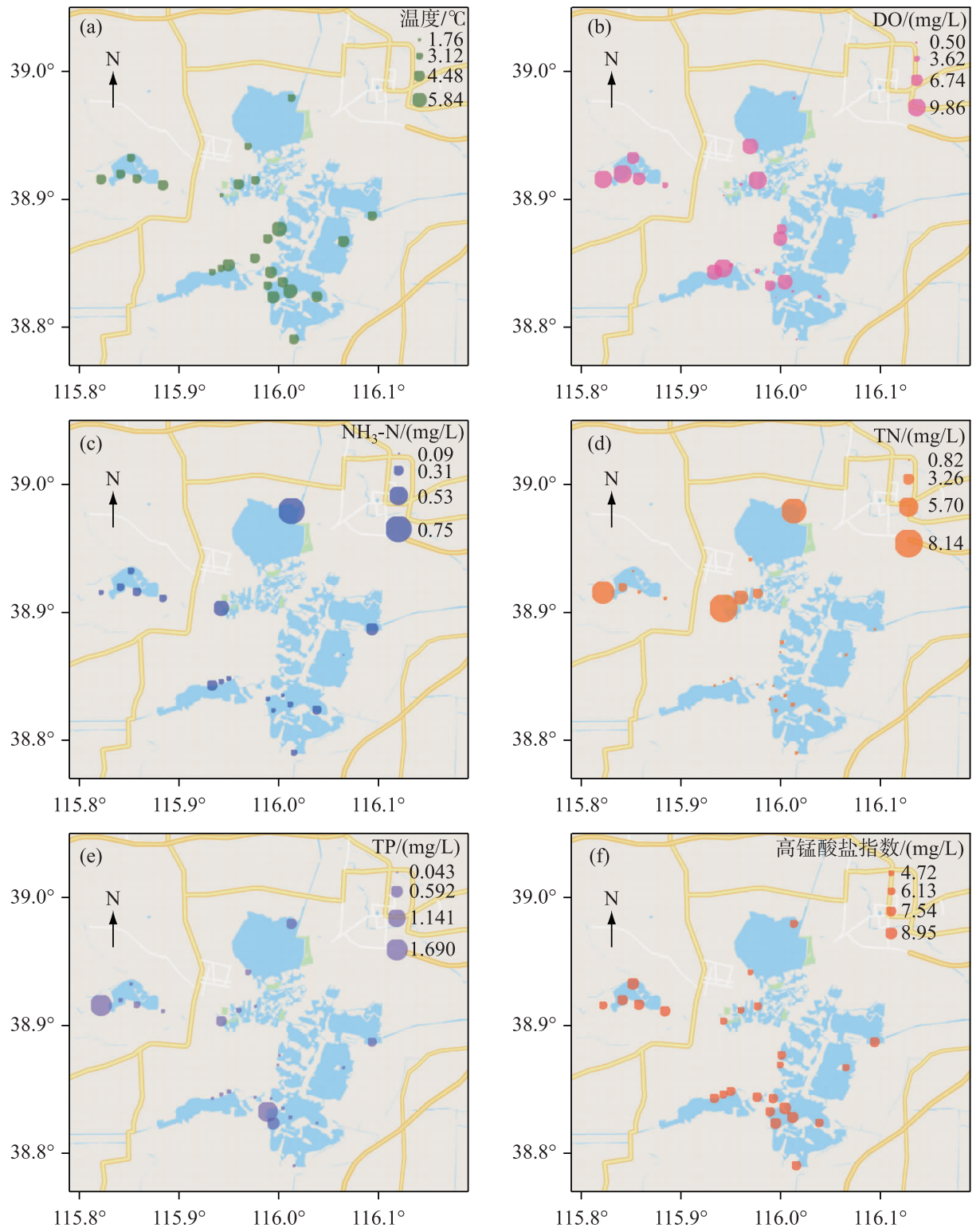

图 2 白洋淀采样点水质基本指标

Fig.2 Basic indicators of water quality of sampling sites in Lake Baiyangdian

2.1.3 水质特征分析 综合图 2 可知, 白洋淀冰封期水体温度波动较小, DO 浓度显示冰封期原始区和人淀区 
较高, 人淀区 $\mathrm{NH}_{3}-\mathrm{N}$ 浓度较高, 高锰酸盐指数在各采样点间相差较小, 各采样点的 TN 和 TP 浓度变化幅度 较大且大多数采样点的 $\mathrm{TN} 、 \mathrm{TP}$ 浓度较高, 超过了 $\mathrm{V}$ 类水体的限值, 这与阳小兰等 ${ }^{[27]}$ 得出的 $\mathrm{TN}$ 、TP 是白洋 淀的主要污染物的结论相一致. Liu 等 ${ }^{[28]}$ 通过研究白洋淀浮游植物的结构变化与理化因子的关系发现白洋 淀的理化因子指标呈季节性变化, 氮、磷浓度在冬季呈升高趋势, 与本文对白洋淀冰封期水体氮、磷浓度呈 较高趋势的结果一致.

表 2 展示了白洋淀与新三湖 ( 白洋淀、洱海、丹江口) ; 老三湖 (太湖、巢湖、滇池); 北方湖泊 (乌梁素海、 呼伦湖、博斯腾湖) 以及北欧湖泊 (维纳恩湖) 的水质状况对比, 根据数据逐一对比可知 ${ }^{[29-37]}$, 在新三湖中, 白 洋淀的 TN 、 TP 浓度波动最大且较高, 洱海与丹江口水质较好, 而白洋淀则呈现出 N、P 污染严重; 通过与老 三湖的对比可知, 除巢湖的 TN 浓度高于白洋淀外, 太湖、滇池的 TN 浓度均低于白洋淀, TP 浓度呈现出白洋 淀最高的状态; 与北方的 3 条典型湖泊及北欧最大湖泊维纳恩湖相比,博斯腾湖与维纳恩湖的 N、P 浓度低 于白洋淀, 乌梁素海和呼伦湖的 TN 浓度高于白洋淀, 但 TP 浓度白洋淀最高; 若不加紧对水体中 N、P 污染 物的治理, 在融冰期随着水体流动加快, 污染物扩散速度增加, 可能导致整个淀区水质受到严重污染, 通过 与新三湖、老三湖、北方湖泊与北欧湖泊的对比可以发现, 白洋淀的 N、P 污染更为明显, 水体富营养化的原 因主要是 $N 、 P$ 浓度超标 ${ }^{[38]}$, 白洋淀冰封期水质中较高的 $N 、 P$ 污染物, 在融冰期随着水体流动加快会大面积 扩散污染淀区水质,因此对水质治理时, 白洋淀的 $N 、 P$ 污染物去除应引起重视.

表 2 白洋淀主要污染指标与其他湖泊比较

Tab.2 Comparison of main pollution indicators of Lake Baiyangdian with other lakes

\begin{tabular}{|c|c|c|c|c|c|}
\hline 湖泊 & 湖泊类型 & $\mathrm{TN} /(\mathrm{mg} / \mathrm{L})$ & $\mathrm{TP} /(\mathrm{mg} / \mathrm{L})$ & 主要污染指标 & 参考文献 \\
\hline 白洋淀 & 新三湖 & $0.84 \sim 8.13$ & $0.04 \sim 1.62$ & $\mathrm{TN} 、 \mathrm{TP}$ & 本研究 \\
\hline 洱海 & & $0.30 \sim 0.56$ & $0.01 \sim 0.02$ & - & {$[32]$} \\
\hline 丹江口 & & $1.29 \sim 1.46$ & $0.03 \sim 0.04$ & - & {$[33]$} \\
\hline 太湖 & 老三湖 & $3.06 \sim 4.90$ & $0.10 \sim 0.27$ & TP & {$[34]$} \\
\hline 巢湖 & & $1.07 \sim 10.22$ & $0.06 \sim 0.47$ & $\mathrm{TN} 、 \mathrm{TP}$ & {$[35]$} \\
\hline 滇池 & & $1.14 \sim 5.54$ & $0.19 \sim 0.69$ & $\mathrm{TN} 、 \mathrm{TP}$ & {$[36]$} \\
\hline 乌梁素海 & 北方湖泊 & $3.9 \sim 9.2$ & $0.11 \sim 0.20$ & $\mathrm{TN}$ & {$[37]$} \\
\hline 呼伦湖 & & $6.24 \sim 9.52$ & $0.36 \sim 0.70$ & $\mathrm{TN} 、 \mathrm{TP}$ & {$[38]$} \\
\hline 博斯腾湖 & & $0.32 \sim 1.79$ & $0.005 \sim 0.019$ & - & [39] \\
\hline 维纳恩湖 & 北欧湖泊 & $0.3 \sim 0.5$ & $0.003 \sim 0.007$ & - & {$[40]$} \\
\hline
\end{tabular}

表 3 是保定市生态环境保护局公布的 2017-2019 年白洋淀四季的监测点实测指标, 根据监测的王家 寨、苯林庄、端村和鸪丁村 4 个点位反映,现有观测的 4 个淀区水质基本都处于 $I V$ 类 $\sim \mathrm{V}$ 类水质间,但也出现 了劣 $\mathrm{V}$ 类水质, 整体上水质处于较差的状态. 根据季节分析, 同一监测点不同季节的水质状况存在波动, 原 因可能是春、夏、秋季节水质流动频繁且人类活动干预较多, 水质中污染物扩散较快; 而冬季结冰, 沉积物在 厌氧状态释放大量污染物, 造成小范围内水质污染, 在融冰期, 随着水体的流动, 污染物开始扩散, 造成第二 年水质较差. 然而, 环保局监测数据仅为 TP 和有机物且监测样点较少未能全面分析整个白洋淀的特征. 尤 其是, 冬季冰封期近 3 年未进行采样分析, 对认识冰封期水体演变特征影响很大. 因此, 本研究在白洋淀冰 封期开展全方位的水体污染特征及水质状况分析, 为以后各淀区水体的靶向治理提供依据.

\section{2 水质评价}

2.2.1 单因子评价 根据水质基本指标分析可知白洋淀冰封期 TN、TP 超标严重, 因此单因子评价法选择 $\mathrm{TN} 、 \mathrm{TP}$ 作为定类项目, 表 4 是运用单因子评价结果对白洋淀冰封期水质进行评价的结果, 可以发现, TN、TP 作为定类项目时, IV 类水占比最高, 均为 $40 \%$. 并且水质中出现了劣 $\mathrm{V}$ 类, 占到了 25 个采样点的 $24 \%$, 人淀 区河流占到了一半, 可能是人淀区河流不仅要承担白洋淀自身的内源污染物, 还要接纳外界河流汇人的外 源污染物, 因此, 人淀区河流水质较差. 综合看单因子评价结果显示出白洋淀冰封期水质呈现出较差的状态 且人淀区河流的水质污染较严重, 这与张铁坚等 ${ }^{[39]}$ 对于人淀区河流的研究结果相一致. 
表 3 白洋淀 2017-2019 年国控监测指标

Tab.3 National control monitoring indicators of Lake Baiyangdian during 2017-2019

\begin{tabular}{|c|c|c|c|c|c|c|c|}
\hline \multirow{2}{*}{ 季节 } & \multirow{2}{*}{ 监测区域 } & \multicolumn{2}{|c|}{2017 年 } & \multicolumn{2}{|c|}{2018 年 } & \multicolumn{2}{|c|}{2019 年 } \\
\hline & & 实测水质 & 主要污染物 & 实测水质 & 主要污染物 & 实测水质 & 主要污染物 \\
\hline \multirow[t]{4}{*}{ 春季 } & 王家寨 & V类 & $\mathrm{TP} 、 \mathrm{COD} 、 \mathrm{BOD}_{5}$ & IV类 & $\mathrm{COD} 、 \mathrm{BOD}_{5}$ & $\mathrm{~V}$ 类 & COD 、TP \\
\hline & 菄林庄 & IV类 & $\mathrm{COD} 、 \mathrm{BOD}_{5}$ & IV类 & COD & IV类 & COD \\
\hline & 端村 & $\mathrm{V}$ 类 & $\mathrm{TP} 、 \mathrm{COD} 、 \mathrm{BOD}_{5}$ & $\mathrm{~V}$ 类 & TP 、COD & 劣 $\mathrm{V}$ 类 & $\mathrm{TP} 、 \mathrm{COD} 、 \mathrm{BOD}_{5}$ \\
\hline & 鸪丁村 & 干淀 & - & \multicolumn{2}{|c|}{ 水位低, 不具备采样条件 } & \multicolumn{2}{|c|}{ 水位较低, 采样点已为地面 } \\
\hline \multirow[t]{4}{*}{ 夏季 } & 王家寨 & $\mathrm{V}$ 类 & $\mathrm{TP} 、 \mathrm{COD} 、 \mathrm{BOD}_{5}$ & $\mathrm{~V}$ 类 & DO 、TP、COD & - & - \\
\hline & 束林庄 & IV 类 & $\mathrm{COD} 、 \mathrm{BOD}_{5} 、 \mathrm{DO}$ & $\mathrm{V}$ 类 & $\mathrm{DO} 、 \mathrm{TP} 、 \mathrm{COD}$ & - & - \\
\hline & 端村 & 劣 V 类 & $\mathrm{TP} 、 \mathrm{COD} 、 \mathrm{BOD}_{5}$ & V类 & TP、COD & - & - \\
\hline & 鸪丁村 & \multicolumn{2}{|c|}{ 水位低, 不具备采样条件 } & \multicolumn{2}{|c|}{ 水位较低, 采样点已为地面 } & - & - \\
\hline \multirow[t]{4}{*}{ 秋季 } & 王家寨 & 劣 V类 & TP 、DO 、COD & III类 & - & - & - \\
\hline & 菄林庄 & IV类 & $\mathrm{COD} 、 \mathrm{BOD}_{5}$ & IV类 & DO 、TP & - & - \\
\hline & 端村 & 劣 $\mathrm{V}$ 类 & TP 、DO 、COD & IV类 & TP 、COD & - & - \\
\hline & 鸪丁村 & \multicolumn{2}{|c|}{ 水位低,不具备采样条件 } & \multicolumn{2}{|c|}{ 水位较低, 采样点已为地面 } & - & - \\
\hline \multirow[t]{4}{*}{ 冬季 } & 王家寨 & $\mathrm{V}$ 类 & $\mathrm{TP} 、 \mathrm{COD} 、 \mathrm{BOD}_{5}$ & V类 & COD & III类 & - \\
\hline & 束林庄 & 结冰 & - & IV类 & COD & $\mathrm{V}$ 类 & TP、COD \\
\hline & 端村 & 劣 $\mathrm{V}$ 类 & $\mathrm{BOD}_{5} 、 \mathrm{TP}$ & $\mathrm{V}$ 类 & TP 、COD & IV类 & $\mathrm{BOD}_{5}$ \\
\hline & 鸪丁村 & \multicolumn{2}{|c|}{ 水位低, 不具备采样条件 } & \multicolumn{2}{|c|}{ 水位较低,采样点已为地面 } & \multicolumn{2}{|c|}{ 水位较低, 采样点已为地面 } \\
\hline
\end{tabular}

表 4 白洋淀采样点水质单因子评价结果

Tab.4 Single factor evaluation result of sampling sites in Lake Baiyangdian

\begin{tabular}{ccccc}
\hline \multirow{2}{*}{ 因子 } & \multicolumn{3}{c}{ 水质标准 } \\
\cline { 2 - 4 } & III类 & IV 类 & V 类 & 劣 V 类 \\
\hline \multirow{2}{*}{$\mathrm{TN}$} & $\mathrm{S} 7 、 \mathrm{~S} 9 、 \mathrm{~S} 10 、 \mathrm{~S} 16 、$ & $\mathrm{~S} 1 、 \mathrm{~S} 3 、 \mathrm{~S} 4 、 \mathrm{~S} 8 、 \mathrm{~S} 13 \sim \mathrm{S} 15 、$ & $\mathrm{~S} 11 、 \mathrm{~S} 12$ & $\mathrm{~S} 2 、 \mathrm{~S} 5 、 \mathrm{~S} 6 、$ \\
& $\mathrm{~S} 17 、 \mathrm{~S} 19 、 \mathrm{~S} 21$ & $\mathrm{~S} 18 、 \mathrm{~S} 23 、 \mathrm{~S} 25$ & $\mathrm{~S} 20 、 \mathrm{~S} 22 、 \mathrm{~S} 24$ \\
$\mathrm{TP}$ & $\mathrm{S} 9 、 \mathrm{~S} 11 、 \mathrm{~S} 13 、 \mathrm{~S} 19$ & $\mathrm{~S} 3 、 \mathrm{~S} 6 、 \mathrm{~S} 8 、 \mathrm{~S} 10 、 \mathrm{~S} 12 、$ & $\mathrm{~S} 1 、 \mathrm{~S} 2 、 \mathrm{~S} 4 、$ & $\mathrm{~S} 7 、 \mathrm{~S} 14 、 \mathrm{~S} 18 、$ \\
& & $\mathrm{~S} 15 \sim \mathrm{S} 17 、 \mathrm{~S} 22 、 \mathrm{~S} 25$ & $\mathrm{~S} 5 、 \mathrm{~S} 23$ & $\mathrm{~S} 20 、 \mathrm{~S} 21 、 \mathrm{~S} 24$ \\
\hline
\end{tabular}

根据以上分析结果, 可以得出在用单因子评价方法对白洋淀水质进行评价时, TN 和 TP 是白洋淀冰封 期水质的限制因子且人淀区河流水质最差.

2.2 .2 综合污染指数评价 对白洋淀冰封期 25 个采样点的综合污染指数进行计算, 结果见图 $3 \mathrm{a}$, 原始区、旅 游区、生活区、养殖区、人淀区的综合污染指数范围分别是 $0.38 \sim 0.66 、 0.46 \sim 0.63 、 0.25 \sim 0.42 、 0.26 \sim 1.05$ 、 $0.29 \sim 1.77$, 数据显示 16 个采样点的水质级别呈轻度污染, 5 个采样点水质呈中度污染, S14、S20、S22、S24 这 4 个采样点的水质到了重度污染级别. S14 后塘采样点是白洋淀的鱼虾养殖区, 以前饲养方式都是将含有大 量氮磷营养物的饵料投人水中, 剩余的饵料则是直接沉人水中, 虽然现在已经禁止了这种投喂方法, 但到了 冬季冰封期, 沉积物释放大量内源污染物, 造成水体污染严重, 这与王亚琼等 ${ }^{[40]}$ 对于白洋淀养殖区水体污染 的研究结果一致; 其余 3 个采样点均属于人淀区河流, S20、S22 采样点不仅承接自身水体, 还接纳上游河流 水质,水质较差. S24 南刘庄府河流经保定市区, 研究表明府河水质主要是受保定市生产生活污水影响较 $大^{[41]}$, 随着保定市生活污水的排人, 导致府河水质受到严重污染, 进而污染其他淀区河流水质, 对白洋淀整 体水质造成巨大威胁.

原始区、旅游区、生活区、养殖区、人淀区 5 个功能区的综合污染指数平均值分别为 $0.52 \pm 0.02 、 0.57 \pm$ $0.01 、 0.32 \pm 0.01 、 0.52 \pm 0.08 、 0.85 \pm 0.13$ (图 3b), 表明人淀区河流的综合污染指数平均值最大且方差最大, 说 明人淀区河流不仅水质较差且内部 6 条河流的综合污染指数波动较大, 白洋淀人淀区呈现出的水质较差的 
原因与䩶河人湖区水质类似 ${ }^{[42]}$, 作为与外界河流进行水质流动的人淀区河流, 汇人的外源污染物较多, 超出 水体自净能力,造成自身河流水质较差,进而对内部河流水质产生威胁; 原始区、旅游区水质次之; 养殖区水 质较差, 虽然现在禁止向水中投放饵料, 但往年水体中残留的饵料污染仍较为严重, 根据现有文献发现 ${ }^{[43]}$, 滇池水体中氮素浓度升高的一个主要原因是剩余饲料沉人水体释放出大量含氮污染物, 由此可知往年堆积 的饲料对于水质仍然是较大的威胁, 需要重点关注, 生活区的水质最好, 且内部采样点呈现出综合污染指数 值接近,均处于轻度污染水体.
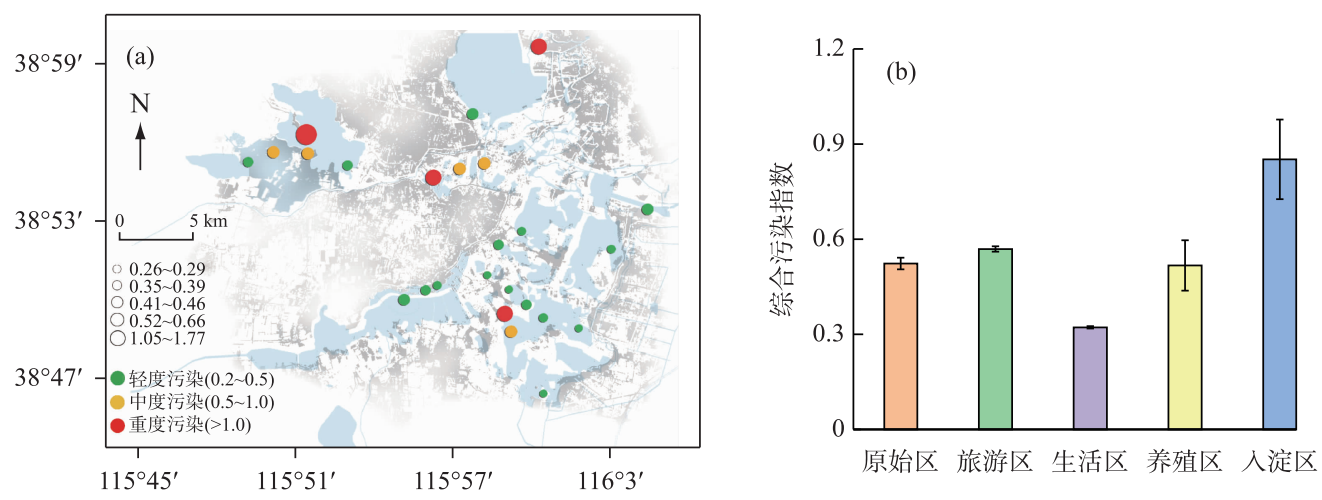

图 3 白洋淀采样点综合污染指数

Fig.3 Comprehensive pollution index of sampling sites in Lake Baiyangdian

2.2.3 主成分分析评价 白洋淀冰封期 25 个采样点的理化参数主成分分析见图 4a, 不仅不同功能区的水质 存在一定差异, 即使相同功能区水质存在的差异也很明显. 人淀区 6 个采样点的水质差异最为明显, 彼此间 偏离较大, 出现这种情况的原因可能是每条人淀区河流承接的上游水系不同, 各项水质因子浓度存在差异, 因此水质差异较为明显; 养殖区、原始区、旅游区 3 个功能区的水质根据图形显示偏离较小, 证明各功能区 内部水质的影响因子偏差不大,生活区各采样点间距离最小, 证明内部水质差异不大. 与第一主成分高度相 关的理化指标是 TN, 因子负载达到了 0.44 , 与第二主成分高度相关的理化指标是 TP, 因子负载达到了 0.55 , 通过这两个数值也可以反映出白洋淀冰封期水质主要受到了 TN 和 TP 的影响, 较高的 N、P 值也将成为白 洋淀水体富营养化的潜在风险, 这一结果与王亚琼等 ${ }^{[40]}$ 对于人淀区和养殖区水体受 $\mathrm{N} 、 \mathrm{P}$ 影响较大的污染 结果相一致.

根据成分得分系数矩阵等相关方程和公式得出 25 个采样点的主成分综合得分, 见图 $4 \mathrm{~b}$, 即能定量描述 各采样点水质的污染程度, 综合得分越高, 水质越差. 水质较差的采样点为 S22 和 S24, 水质较好的采样点为 S8; S22 和 S24 采样点分别为瀑河藻苲淀人淀口和南刘庄府河人淀口, 这 2 条人淀河流都属于大清河南支河 流, 瀑河藻苲淀人淀口位于白洋淀的西部, 为季节性泄洪河道, 南刘庄府河人淀口是上游保定市排放生活污 水、工农业生产污水的排泄通道, 受人类活动影响较频繁, 汇人的外源污染物较多, 致使水质较差. S8 平阳淀 位于整个淀区的东部,远离人淀区河流的污染,淀区水体受到的污染较小,因此水质较好.

从 5 个功能分区分析, 人淀区水质最差,生活区的水质较好. 通过数据分析可知, 白洋淀各淀区水质存 在一定差异,一方面与水体在淀区的迁移流向有关, 另一方面与淀区及淀区周边的污染物排放有关, 白洋淀 是封闭性湖泊, 淀区地势起伏不大, 淀区内水体流动不明显. 因此位于西部的人淀区河流在接纳外源和内源 污染物时, 自净能力较弱, 水质相较其他功能区较差, 位于中部和东部的生活区因远离人淀区河流的污染以 及政府对于白洋淀水体的治理,水质相对较好.

通过 3 种评价方法对于白洋淀冰封期水质状况的评价可知, 虽然 3 种评价方法分析角度不同, 但均表现 出冰封期人淀区水质最差, 虽然处于冰封期, 但依旧与外界河流存在水体流动, 汇人其中的外源污染物可能 较多. 人淀区作为承接白洋淀与外界水系的纽带, 其水质对白洋淀水环境影响较大, 因此在对白洋淀水质进 行治理时, 人淀区水质的治理应给予重点关注, 只有有效改善人淀区河流的水质,才是净化白洋淀水体的 

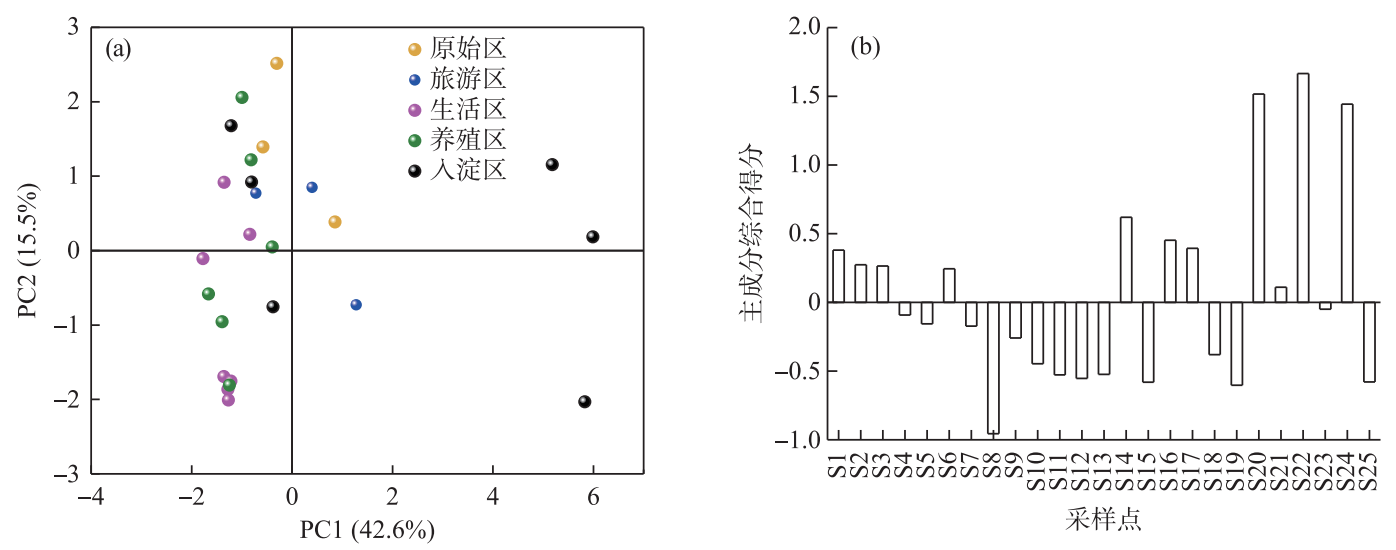

图 4 白洋淀冰封期采样点主成分分析

Fig.4 Principal component analysis of sampling sites in Lake Baiyangdian during the freezing period

关键.

2.2.43 种评价方法的对比运用单因子评价法、综合污染指数法、主成分分析法 3 种评价方法对白洋淀水 质进行评价. 单因子评价法简单直观, 能够对白洋淀水质进行定性评价, 利用数据判定各采样点的水质等 级, 得出 TN TP 是白洋淀水质的限制因子, 但单因子评价法不能对同一等级的水质断面进行更详细的优劣 排序. 综合污染指数法和主成分分析计算相对复杂, 能对水质进行定量分析, 对各采样点的水质情况进行优 劣排序, 对 5 个功能区的水质进行整体分析, 通过这两种方法的分析, 25 个采样点中, S22 和 S24 的水质是最 差的, S8 平阳淀因远离人淀区河流的影响, 水质较好. 按功能区分析, 人淀区河流不仅要承载白洋淀自身水 质的污染源, 还要承载外界河流汇人的污染物质, 因此水质最差; 养殖区、生活区和旅游区的水质由于受到 人类活动和淀区自身水生植物腐烂产生的污染物质的影响, 水质次之; 原始区因属于未开发区域, 人类活动 干预较少, 因此水质较好.

3 种评价方法中, 虽然各有其优缺点, 但主成分分析法主要是根据方差累计贡献率作为因子权重进行数 据处理, 对于数据的处理较复杂, 但得出的结果相对客观准确, 与前 2 种方法相比, 对于白洋淀冰封期水质 评价得出的结果参考价值更大. 运用这 3 种评价方法可以从不同角度评价白洋淀各淀区水质的污染状况, 故运用多种评价方法能更客观全面的反映白洋淀冰封期水质状况与污染特征.

\section{3 结论}

1) 白洋淀冰封期水体温度在 $1.76 \sim 5.84^{\circ} \mathrm{C}$, 温差波动较小; 各淀区水质的 DO 浓度变化幅度较大, 原始 区内 DO 浓度较高; 人淀区河流的 $\mathrm{NH}_{3}-\mathrm{N}$ 浓度较高; 25 个采样点中 $\mathrm{TN} 、 \mathrm{TP}$ 浓度变化幅度较大且较高; 25 个 采样点的高锰酸盐指数较为接近, 但养殖区的高锰酸盐指数较大.

2 ) 单因子评价结果显示, $\mathrm{TN}$ 参与评价时, $\mathrm{V}$ 类和劣 $\mathrm{V}$ 类水质占到了总采样点的 $8 \%$ 和 $24 \%$; $\mathrm{TP}$ 参与评 价时, $\mathrm{V}$ 类和劣 $\mathrm{V}$ 类水质占到了总采样点的 $20 \%$ 和 $24 \%$, 白洋淀冰封期水质总体呈现出较差的状态.

3) 综合污染指数法显示白洋淀冰封期各采样断面水质的污染程度集中在轻度污染一重度污染间, 生活 区水质最好, 人淀区河流的水质最差且每条河流受到的污染源相差较大, 在对白洋淀水质进行治理时, 人淀 区河流水质将成为治理重点.

4) 主成分分析结果显示人淀区河流水质差异性最为明显, 与综合污染指数得出的结果一致,各功能区 水质主要受 TN、TP 两个指标的影响较大, 较高的 N、P 浓度可能会引起水体的富营养化, 因此应加紧对白洋 淀水体中 $N 、 P$ 污染物的去除.

\section{4 参考文献}

[ 1 ] Xu F, Yang ZF, Chen B et al. Ecosystem health assessment of Lake Baiyangdian based on thermodynamic indicators. Pro- 
cedia Environmental Sciences, 2012, 13: 2402-2413. DOI: 10.1016/j.proenv.2012.01.229.

[ 2 ] Li H, Shen HY, Li SJ et al. Effects of eutrophication on the benthic-pelagic coupling food web in Lake Baiyangdian. Acta Ecologica Sinica, 2018, 38(6) : 2017-2030. [李华, 沈洪艳, 李双江等. 富营养化对白洋淀底栖-浮游耦合食物网结 构和功能的影响. 生态学报, 2018, 38(6): 2017-2030.]

[ 3 ] Zhu YY, Jin X, Tang WZ et al. Comprehensive analysis of nitrogen distributions and ammonia nitrogen release fluxes in the sediments of Lake Baiyangdian, China. Journal of Environmental Sciences (China), 2019, 76: 319-328. DOI: 10. 1016/j.jes.2018.05.024.

[ 4 ] Zhao Y, Yang Z, Li Y. Investigation of water pollution in Lake Baiyangdian, China. Procedia Environmental Sciences, 2010, 2 : 737-748. DOI: 10.1016/j.proenv.2010.10.085.

[ 5 ] Wang Y, Liu LS, Shu JM et al. Community structure of phytoplankton and the water quality assessment in Lake Baiyangdian. J Lake Sci, 2011, 23(4) : 575-580. DOI: 10.18307/2011.0413. [王瑜, 刘录三, 舒俭民等. 白洋淀浮游植物群落 结构与水质评价. 湖泊科学, $2011,23(4): 575-580$.]

[ 6 ] Qi Y, Wang ZY, Pei YS. Evaluation of water quality and nitrogen removal bacteria community in Fuhe River. Procedia Environmental Sciences, 2012, 13: 1809-1819. DOI: 10.1016/j.proenv.2012.01.174.

[ 7 ] Yang H, Zhang GZ, Yang XN et al. Comprehensive evaluation on water environment quality of the Tao River based on fuzzy comprehensive. Environmental Science \& Technology, 2016, 39(S1): 380-386, 392. [杨浩, 张国珍, 杨晓妮等. 基于模糊综合评判法的洮河水环境质量评价. 环境科学与技术, 2016, 39(S1)：380-386, 392.]

[ 8 ] Wang ZK, Zhang KF, Liu L. Optimization of single factor index method in groundwater contamination assessment. Environmental Engineering, 2016, 34(S1) : 810-812, 816. [王志垲, 张克峰, 刘雷. 地下水污染评价中单因子指数法的优 化. 环境工程, 2016, 34(S1): 810-812, 816.]

[ 9 ] He XL, Wu YH, Zhou J et al. Hydro-chemical characteristics and quality assessment of surface water in Gongga Mountain Region. Environmental Science, 2016, 37(10): 3798-3805. [何晓丽, 吴艳宏, 周俊等. 贡嘎山地区地表水化学特征 及水环境质量评价. 环境科学, 2016, 37 (10): 3798-3805.]

[10] Sun T, Zhang MX, Li MM et al. River water quality evaluation based on correspondence analysis and comprehensive pollution index method. Environmental Science \& Technology, 2014, 37(4): 185-190. [孙涛, 张妙仙, 李苗苗等. 基于对应 分析法和综合污染指数法的水质评价. 环境科学与技术, 2014, 37(4): 185-190.]

[11] Wang J, Fu Z, Qiao H et al. Assessment of eutrophication and water quality in the estuarine area of Lake Wuli, Lake Taihu, China. Science of the Total Environment, 2019, 650 (Pt 1) : 1392-1402. DOI: 10.1016/j. scitotenv.2018.09.137.

[12] Li S, Ding XR, Pang J et al. The spatially and temporally dynamic variation of water quality in Tai Lake based on principle component analysis. Environmental Science and Technology, 2012, 25(3): 44-47. [李森, 丁贤荣, 潘进等. 基于主成 分分析的太湖水质时空分布特征研究. 环境科技, 2012, 25(3): 44-47.]

[13] Yang W, Xu K, Lian J et al. Multiple flood vulnerability assessment approach based on fuzzy comprehensive evaluation method and coordinated development degree model. Journal of Environmental Management, 2018, 213 (1) : 440-450. DOI: $10.1016 /$ j.jenvman.2018.02.085.

[14] Tomas D, Čurlin M, Maric AS. Assessing the surface water status in Pannonian ecoregion by the water quality index model. Ecological Indicators, 2017, 79(8) : 182-190. DOI: 10.1016/j.ecolind.2017.04.033.

[15] Zhu YY, Jin X, Meng X et al. Study on ammonia nitrogen release flux in the sediment-water interface of Lake Baiyangdian. Acta Scientiae Circumstantiae, 2018, 38(6) : 2435-2444. [朱曜曜, 金金金, 孟金金等. 白洋淀沉积物氨氮释放通量研究. 环境科学学报, 2018, 38(6): 2435-2444.]

[16] Du YH, Liu C, Chen KN et al. Occurrence and internal loadings of nitrogen and phosphorus in the sediment of Lake Baiyangdian. J Lake Sci, 2018, 30(6) : 1537-1551. DOI: 10.18307/2018.0606. [杜奕衡, 刘成, 陈开宁等. 白洋淀沉积 物氮磷赋存特征及其内源负荷. 湖泊科学, 2018, 30(6) : 1537-1551.]

[17] Xia L L, Liu RZ, Zao YW. Correlation analysis of landscape pattern and water quality in Baiyangdian watershed. Procedia Environmental Sciences, 2012, 13: 2188-2196. DOI: 10.1016/j.proenv.2012.01.208.

[18] Xue PY, Zhao QL, Wang YQ et al. Distribution characteristics of heavy metals in sediment-submerged macrophyte-water systems of Lake Baiyangdian. J Lake Sci, 2018, 30(6) : 1525-1536. DOI: 10.18307/2018.0605. [薛培英, 赵全利, 王 亚琼等. 白洋淀沉积物-沉水植物-水系统重金属污染分布特征. 湖泊科学, 2018, 30(6): 1525-1536.]

[19] Gao QS, Zhao YH, Jiao LX et al. Pollution characteristics and health risk assessment of volatile organic compounds in 
Lake Baiyangdian. Environmental Science, 2018, 39(5): 2048-2055. [高秋生, 赵永辉, 焦立新等. 白洋淀水体挥发 性有机物污染特征与风险评价. 环境科学, 2018, 39(5): 2048-2055.]

[20] Xu S, Liu CQ, Dong MH et al. The spatio-temporal variation of alkaline phosphatase activity in water and sediment of Lake Baiyangdian and its impact factors. Acta Scientiae Circumstantiae, 2013, 33(12): 3317-3323. [徐爽, 刘存歧, 董梦荟 等. 白洋淀水体和沉积物中碱性磷酸酶活性的时空分布及其影响因素. 环境科学学报, 2013, 33(12): 3317-3323. ]

[21] Editorial Board of Water and Wastewater Monitoring and Analysis Methods, Ministry of Environmental Protection of the People's Republic of China eds. Water and Wastewater Monitoring and Analysis Methods: 4th edition. Beijing: China Environmental Science Press, 2002. [ 国家环境保护总局《水和废水监测分析方法》编委会. 水和废水监测分析方法: 第 4 版. 北京: 中国环境科学出版社,2002.]

[22] Guo J, Wang CM, Huang DZ et al. Pollution characterization and water quality assessment of Dongting Lake. Environmental Chemistry, 2019, 38(1)：152-160. [ 郭晶, 王丑明, 黄代中等. 洞庭湖水污染特征及水质评价. 环境化学, $2019, \mathbf{3 8}(1): 152-160$. ]

[23] Shu L, Zhang ZQ, Lv J. The ecological environment monitoring and pollution evaluation of present water quality in Suining Section of Fujiang River. Sichuan Environment, 2013, 32(6): 49-53. [舒丽, 张政权, 吕娟. 涪江流域遂宁段生态环 境监测与水质污染现状评价. 四川环境, 2013, 32(6): 49-53.]

[24] Wang LJ, Wang X, Liu LS et al. Multivariate analysis of water factors in Dongting Lake. Research of Environmental Sciences, 2013, 26(1) : 1-7. [王丽婧, 汪星, 刘录三等. 洞庭湖水质因子的多元分析. 环境科学研究, 2013, 26(1): 1-7.]

[25] Yang J, Strokal M, Kroeze C et al. Nutrient losses to surface waters in Hai He basin: A case study of Guanting Reservoir and Lake Baiyangdian. Agricultural Water Management, 2019, 213: 62-75. DOI: 10.1016/j.agwat.2018.09.022.

[26] Hu XM, Cui J, Pei YS et al. Organic matter characteristics of sediment in Lake Baiyangdian in autumn-winter alternate season. Research of Environmental Sciences, 2019, 32(4) : 636-646. [胡晓明, 崔骏, 裴元生. 秋冬交替季节白洋淀沉 积物有机质特性研究. 环境科学研究, 2019, 32(4): 636-646.]

[27] Yang XL, Zhang RC, Mao X et al. Analysis of spatial and temporal distribution of nitrogen and phosphorus and eutrophication of water in Lake Baiyangdian. Jiangsu Agricultural Sciences, 2018, 46(24): 370-373. [阳小兰, 张茹春, 毛欣等. 白洋淀水体氮磷时空分布与富营养化分析. 江苏农业科学, 2018, 46(24) : 370-373.]

[28] Liu CQ, Liu LS, Shen HT. Seasonal variations of phytoplankton community structure in relation to physico-chemical factors in Lake Baiyangdian, China. Procedia Environmental Sciences, 2010, 2: 1622-1631. DOI: 10. 1016/j. proenv. 2010. 10.173 .

[29] Chen XH, Qian XY, Li XP et al. Long-term trend of eutrophication state of Lake Erhai in 1988-2013 and analyses of its socio-economic drivers. J Lake Sci, 2018, 30(1) : 70-78. DOI: 10.18307/2018.0107. [陈小华, 钱晓雍, 李小平等. 洱 海富营养化时间演变特征 (1988-2013 年) 及社会经济驱动分析. 湖泊科学, 2018, 30 (1) : 70-78.]

[30] Zhang X, Xiong J, Cheng JX et al. The spatial distribution and long-term variation trend of water quality of Danjiangkou Reservoir in Hubei Province. Environmental Monitoring in China, 2016, 32(1): 64-69. [张煦, 熊晶, 程继雄等. 丹江 口水库湖北库区水质分区及长期变化趋势. 中国环境监测, 2016, 32(1): 64-69.]

[31] Wu ZS, Wang XL, Chen YW et al. Assessing river water quality using water quality index in Lake Taihu Basin, China. Science of the Total Environment, 2018, 612: 914-922. DOI: 10.1016/j.scitotenv.2017.08.293.

[32] Zhang H, Yang X. Application of single factor water quality identification index method for water quality assessment of Chaohu Lake Basin. Anhui Agricultural Science Bulletin, 2018, 24(10): 116-119, 163. [张辉, 杨雄. 单因子水质标识 指数法在巢湖流域水质评价中的应用. 安徽农学通报, 2018, 24(10): 116-119, 163.]

[33] Yang K, Yu ZY, Luo Y et al. Spatial and temporal variations in the relationship between lake water surface temperatures and water quality-A case study of Dianchi Lake. Science of the Total Environment, 2018, 624: 859-871. DOI: 10.1016/ j.scitotenv.2017.12.119.

[34] Li X, Yang QM, Gou MM. Temporal and spatial distribution of water quality in Lake Wuliangsuhai, Inner Mongolia. Ecology and Environmental Sciences, 2011, 20(Z2) : 1301-1306. [李兴, 杨乔媚, 勾芒芒. 内蒙古乌梁素海水质时空分布 特征. 生态环境学报, 2011, 20(Z2): 1301-1306.]

[35] Guo ZY, Li CY, Shi XH et al. Temporal and spatial distributions and eutrophication of nutrients in the ice-cold period of 
Hulun Lake, China. Environmental Chemistry, 2019, 38(5): 1180-1189. [ 郭子扬, 李畅游, 史小红等. 呼伦湖冰封期 N、P 时空分布及富营养化特征. 环境化学, 2019, 38(5) : 1180-1189.]

[36] Xie GJ, Zhang JP, Tang XM et al. Spatio-temporal heterogeneity of water quality (2010-2011) and succession patterns in Lake Bosten during the past 50 years. J Lake Sci, 2011, 23(6): 837-846. DOI: 10.18307/2011.0603. [谢贵娟, 张建 平, 汤祥明等. 博斯腾湖水质现状 (2010-2011 年) 及近 50 年来演变趋势. 湖泊科学, 2011, 23(6): 837-846. ]

[37] Dahl M, Wilson DI. Is Lake Vänern well mixed? A statistical procedure for selecting model structure and resolution. Journal of Great Lakes Research, 2004, 30(2) : 267-276. DOI: 10.1016/S0380-1330(04)70344-5.

[38] Carpenter SR. Eutrophication of aquatic ecosystems: Bistability and soil phosphorus. Proceedings of the National Academy of Sciences of the United States of America, 2005, 102(29): 10002-10005. DOI: 10.1073/pnas.0503959102.

[39] Zhang TJ, Wang M, Peng YX et al. Survey of zooplankton communities and evaluation of water quality in the upstream urban inland river of Lake Baiyangdian. Environmental Engineering, 2016, 34(3): 166-169, 132. [张铁坚, 王朦, 彭艳 侠等. 白洋淀上游城市内河浮游动物群落调查与水质评价. 环境工程, 2016, 34(3): 166-169, 132.]

[40] Wang YQ, Xue PY, Geng LP et al. Distribution characteristics of nitrogen and phosphorus in sediments-submerged macrophytes-water systems of Lake Baiyangdian. Journal of Soil and Water Conservation, 2017, 31(3): 304-309. [王亚琼, 薛 培英, 耿丽平等. 白洋淀沉积物-沉水植物-水系统氮、磷分布特征. 水土保持学报, 2017, 31(3): 304-309.]

[41] Wang J, Gao G, Pei YS et al. Sources and transformations of nitrogen in the fuhe river of the Lake Baiyangdian. Environmental Science, 2010, 31(12) : 2905-2910. [王珺, 高高, 裴元生等. 白洋淀府河中氮的来源与迁移转化研究. 环境 科学, $2010, \mathbf{3 1}(12): 2905-2910$.

[42] Lian HS, Liu HB, Li XD et al. Analysis of spatial variability of water quality and pollution sources in Lihe River Watershed, Taihu Lake Basin. Environmental Science, 2017, 38(9): 3657-3665. [连慧姝, 刘宏斌, 李旭东等. 太湖薏河小 流域水质的空间变化特征及污染物源解析. 环境科学, 2017, 38(9): 3657-3665.]

[43] Gao W, Howarth RW, Swaney DP et al. Enhanced N input to Lake Dianchi Basin from 1980 to 2010: Drivers and consequence. Science of the Total Environment, 2015, 505: 376-384. DOI: 10.1016/j.scitotenv.2014.10.016. 